\title{
Enhancement of Seismic Data Processing and Interpretation of Fracture Zones on the Upper Part of Granitic Basement in Cuu Long Basin, Vietnam
}

\author{
Mai Thanh TAN ${ }^{1}$, Mai Thanh HA ${ }^{2}$, Kurt J. MARFURT ${ }^{3}$, \\ Nguyen Trung HIEU ${ }^{4}$, and Nguyen Thi My HANH ${ }^{2}$ \\ ${ }^{1}$ Hanoi University of Mining and Geology, Dong Ngac, Tu Liem, Hanoi, Vietnam \\ e-mail: mttan44@gmail.com \\ ${ }^{2}$ Petrovietnam Exploration and Production Corporation, \\ Tran Duy Hung, Hanoi, Vietnam \\ ${ }^{3}$ The University of Oklahoma, Norman, Oklahoma, USA \\ ${ }^{4}$ Vietnam Petroleum Institute, Trung Kinh, Tu Liem, Hanoi, Vietnam
}

\begin{abstract}
The fractured granite basement is the primary oil and gas reservoir in the Cuu Long Basin, Vietnam. Due to the complexity of this nonlayered unconventional target, combined with complicated fault and fracture systems, the seismic data quality near and within the basement section is very low. For this reason, it is important to apply improved seismic data processing workflows, filtering and migration techniques, as wells as attribute processing methods to enhance the imaging quality.

Our studies show that applying different types of filters, including the f-k, Radon transform and Tau-P, improves signal to noise ratio, removing multiples, revealing basement's top and its related fractured and fault zones. In addition, the application of multi-arrival-solution migration algorithms, such as Kirchhoff Migration and Controlled Beam Migration, provides improved imaging for identifying basement top and faults and fractures within the basement. Furthermore, the application of seismic attributes such as curvature, apparent dip, or energy gradient, is
\end{abstract}

Ownership: Institute of Geophysics, Polish Academy of Sciences;

(C) 2016 Tan et al. This is an open access article distributed under the Creative Commons Attribution-NonCommercial-NoDerivs license,

http://creativecommons.org/licenses/by-nc-nd/3.0/. 
important in locating faults and fractures, whereas mapping of intensity and orientation of such structures assists the delineation of "sweet spots" and assists the planning of exploration.

Key words: Cuu Long Basin, fractured basement, faults, filters, migration, imaging, attributes.

\section{INTRODUCTION}

The Cuu Long Basin is one of major Cenozoic marginal sedimentary basins of the continental shelf of Vietnam. This basin comprises fragmented Mesozoic basement complexes and overlying Cenozoic strata of differing age, origin and spatial distribution. The basement complexes, which compose mostly felsic intrusive and subordinate sedimentary rocks, are commonly strongly fractured, dismembered and partly hydrothermally altered as a consequence of numerous tectonic events. The basement rocks were exposed to weathering before subsidence and covered by Cenozoic sedimentary units during the crustal rifting and basin formation processes. These processes created local significant structural variability such as horst and grabens, a network of fractures with sufficient pore space and permeability within the basement complexes. All of these features have contributed to the formation of a unique type of hydrocarbon reservoirs within the basement granitic rocks of the Cuu Long Basin, which became primary targets for oil and gas exploration in Vietnam.

In the Cuu Long Basin, petroleum exploration activities depend largely on the results of seismic data acquisition and analysis, especially for the basement complexes. However, due to the non-layered nature and the structural complexity of the fractured basement, the seismic data contain a lot of noise and multiples. Although seismic processing improves data quality for Cenozoic sediments, the seismic data quality for fractured zones in the basement is still very limited.

The resolution of seismic data in fractured basement is often very low and therefore it is difficult to identify sufficient structural information and correlation interpreted data with well logs. Therefore, it is important to improve the seismic data quality, remove noise and multiples, enhance faults and fracture related signals for assisting the geological interpretation and identifying exploration targets as well as optimizing well locations. This can be done by using different types of filters, including f-k, Tau-P, Radon transform to reprocess the seismic data. In addition, applying multiple-arrival migration approach such as Controlled Beam Migration (CBM) also assists revealing complicated, steeply dipping faults. Furthermore, application of geometric attributes, such as apparent dips and energy gradients, using shaded-relief maps from orthogonal attribute scan help highlighting fault sys- 
tems. All these processes help improving the interpretation of fault and fracture networks in the basement complexes and providing better results for the identification of potential reservoirs and exploration targets. This paper describes the results of those processing sequences of a seismic dataset from Cuu Long Basin to reveal the sub-unconformity, structural complex basement architectures.

\section{GENERAL GEOLOGY OF CUU LONG BASIN}

The Cuu Long Basin is located on the southeast continental shelf of Vietnam (Fig. 1). This basin is a typical intracratonic rift basin formed on the PreCenozoic basement, filled with Miocene and Oligocene terrigenous sedimentary sequences (Tapponier et al. 1986, Le Pichon et al. 1992, Gwang et al. 2001, Dong 2012). The sedimentary sequences are variable greatly in spatial distribution and thickness. In some portion of the basin, the sediment's thickness is up to about $7000-8000 \mathrm{~m}$. The Pre-Cenozoic basement rocks comprise dominantly the Jurassic to Paleocene intrusive complexes and subordinate extrusive rocks and sedimentary units. The structure of the PreCenozoic basement in the Cuu Long basin is very complex, which was caused by multiple deformational events, hydrothermal alteration, uplift, and weathering processes (Dong et al. 1999, Tan 1990).

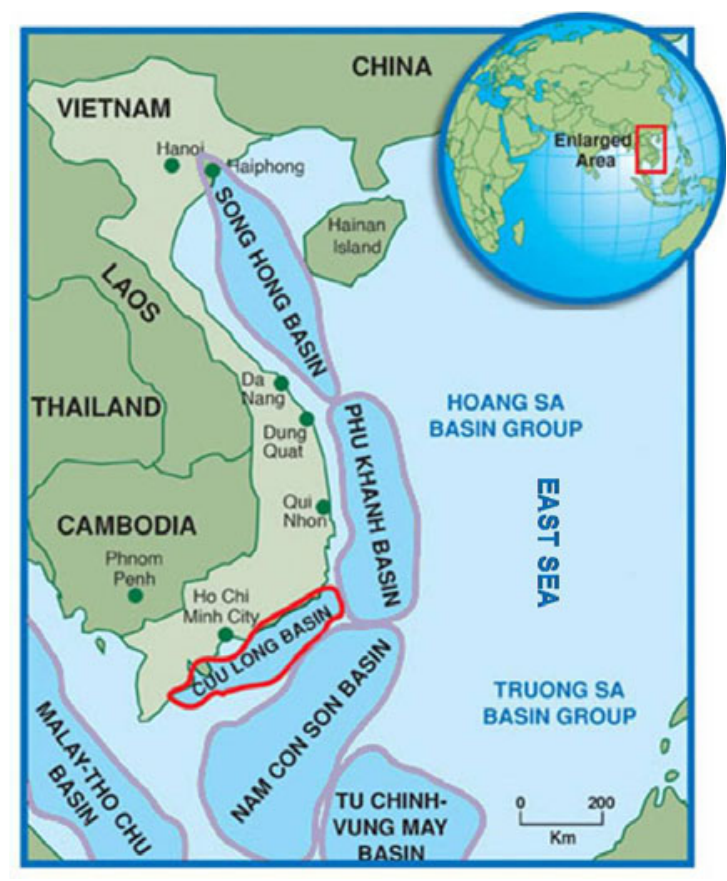

Fig. 1. Cuu Long Basin in the Southeast Continental Shell of Vietnam (image courtesy of PetroVietnam). 

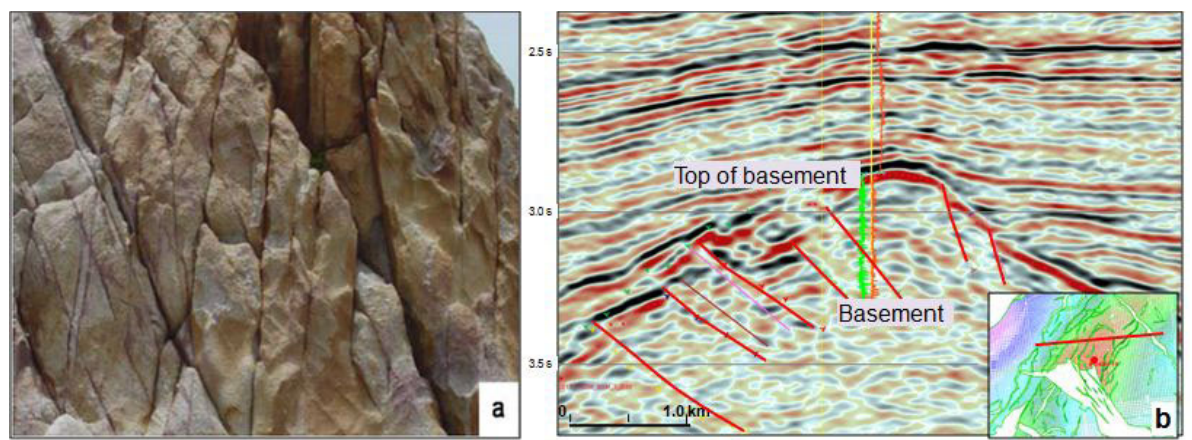

Fig. 2. Outcrops (a) and seismic cross-section (b) showing faults and fractures inside granite basement.

The multiple deformational events created numerous tectonic and/or solution-enhanced fracture systems with different directions and sizes in the basement. The deformation processes include shearing, extension and compression, which produced a network of cross-cutting faults and fractures within the basement rocks as well as commonly created horst and graben structures. The fracture and/or fault systems in the basement are variable in both trend and dip but are commonly steeply dipping $\left(55-70^{\circ}\right)$ (Cuong and Warren 2009, Duc 2014). Highly fractured zones with good reservoir properties are usually found in the basement highs that are controlled by regional-scale faults. In addition, the influence of surface processes on the basement rocks prior to the subsidence to form sedimentary basin, particularly weathering, also created thick zones of high pore space within the upper part of the basement complexes, and, as such, were improving basement reservoir quality (Areshev et al. 1992, Tan 1995, San et al. 1997). The hydrothermal processes, however, play negative role in reservoir quality by the infiltration of secondary materials into the pore space and lead to the reduction of porosity and permeability of the basemen rocks (Tan and Bo 1997).

Thus, the combined effects of tectonic deformation and subsequent subsurface processes in the basement magmatic rocks produced a mixture of fractures, vugs, and empty spaces that are favorable for hydrocarbon to migrate from the Oligocene-Miocene source rocks and accumulate into the highs near the top of the basement. Figure 2 shows faults and fractures of granite basement on (a) outcrops and (b) seismic section.

\section{METHODS FOR IMPROVING FAULTS AND FRACTURES SIGNATURE WITHIN BASEMENT}

The unique characteristics of basement reservoir require a careful evaluation and unique processing and interpretation methods. Identification of distribu- 
tion of the fracture zones is important for extrapolation of favorable target for exploration (Tan and Thap 2001). However, in the absence of stratified, coherent reflectors, illumination of basement faults is more problematic than illumination of faults within the sedimentary cross-sections. With the complex interference pattern, non-layered and steeply dipping nature of faults and fractures, it is important to enhance seismic data processing, reducing noise and multiple reflections (Tan and Ha 2013). Seismic filters such as f-k, Tau-P, Radon transform were used to remove multiple reflections, revealing the weaker seismic signals. Seismic migration methods such as Kirchhoff Migration and Controlled Beam Migration (CBM) were used to image steeply dipping fault and fracture plane events. And selective seismic attributes methods were applied to further delineate and map out fractures.

\subsection{Multiple attenuation by using filters}

Analysis of seismic profiles from Cuu Long Basin has shown that seismic signals reflected from the fractured granitic basement is of very low quality, containing a lot of noise and multiples. Multiples are related with strong reflection surfaces of the Miocene, Oligocene sediments, and top-basement. Multiple suppression methods can be used based on either prediction criteria or normal move-out differential to improve the weak primary reflections. Using filters such as $\mathrm{f}-\mathrm{k}$, Tau-P, and Radon transform enhances the signal-tonoise ratio and improves seismic signals significantly.

F-k filtering: Multiple reflections are filtered from seismograms by transforming them into an $\mathrm{f}-\mathrm{k}$ array representing amplitude as a function of frequency $(f)$ and wave number $(k)$. Noise and seismic signals may overlap in time domain, but are distinguishable in $\mathrm{f}-\mathrm{k}$ plots, because of the difference in frequency, and wave number between noise and signal. The inverse of the $\mathrm{f}-\mathrm{k}$ transform of the multiple reflections is generated. The $\mathrm{f}-\mathrm{k}$ array of the seismograms is filtered by weighting all samples with the inverse of the $\mathrm{f}-\mathrm{k}$ transform of the multiple reflections (Duncan and Beresford 1994).

Tau-P filtering: is an invertible transformation of seismic shot records expressed as a function of time and offset into the intercept time $(t)$ and ray parameter $(p)$ domain. The main advantage of this transformation is to present a point source shot record as a series of plane wave experiments. The data in this "dip" domain then can be transformed back into the time domain. An un-stacked seismic record or a common-midpoint gather can be described in terms of slope $d t / d x=p$ and intercept time $\tau$, the arrival time $t$ obtained by prospecting the slope back to $x=0$ (Sheriff 1999). Hyperbolic reflections are then transformed into ellipses, straight events such as head waves and direct wave into points. Filtering can be done on the Tau-P map and the filtered result transformed back into record. Multiples often have a 
greater move-out than primaries arriving at the same time. Multiples are periodic in the Tau-P domain, so that it can be suppressed by applying predictive deconvolution in this domain (Benoliel et al. 1987, van der Baan and Kendall 2002). After normal move-out correction, errors are approximately parabolic and tend to map to points in the parabolic Radon domain.

Radon transform: Radon transforms map data before and after move-out correction into points, and multiples can be recognized in the Radon domain. The identified multiple signals can then be subtracted from the data to improve the interpretation process. Radon transforms can effectively model such events, which can then be subtracted from the original data. The Radon transform attempts to more equally suppress multiples for all traces, including near- and far-offset traces (Chapman 1981, Foster and Mosher 1992).

Thus, using filters such as $\mathrm{f}-\mathrm{k}$, Tau-P, and Radon transform for multiple attenuation is not only successful in improvement of seismic signals for sedimentary units but also works well in fractured, non-layered and structural complex basement in the Cuu Long Basin.

\subsection{Improving image by using Seismic Migration}

Migration of seismic data corrects reflection from dipping surface to their true positions, collapses diffractions, increases spatial resolution and resolves areas of complex geology. A major difference in migration algorithms arises from the way the velocity field is utilized (Gardner 1985, Wang and Pann 1996). Kirchhoff Migration is one of seismic migration methods that are extensively used in both layered environment and non-layered fractured basement by summing the energy along diffraction curves (Sun et al. 2000, Yilmaz 2001). The advantage of this type of migration is that it can enhance signals of steeply dipping objects and moderate lateral velocity variations. In a single-arrival migration algorithm, only one arrival is imaged, depending on certain predefined criteria. This is the weakness of Kirchhoff Migration method that requires ray-tracing to handle strong lateral velocity variations.

In order to reduce the disadvantage, Controlled Beam Migration (CBM) can handle multi-arrival ray paths, and preserve steeply dipping reflections, resulting in a cleaner image (Raz 1987, Hill 2001, Gray et al. 2009). A good review of CBM with applications to this study can be found in Sun et al. (2007), Bone et al. (2008), and Elkady et al. (2008).

\subsection{Improving image by using Geometrical Attributes}

For further identification of fault signature, the attribute illumination approach has been applied to well-established vector attributes including structural dip and azimuth and amplitude energy gradients to provide greater interpreter interaction (Chopra and Marfurt 2007, Ha et al. 2014). Based on 
Barnes (2003), we could mathematically generate simple axis rotations and project the two orthogonal dip or energy gradient components along the surface against the direction of illumination. A planar surface, such as dipping horizon or faults, can be presented by its true dip azimuth $\theta$ and strike $\psi$. The true dip $\theta$ can be presented by apparent $\operatorname{dips} \theta_{x}$ and $\theta_{y}$ along the $x$ and $y$ axes. For time-migrated seismic data, it is more convenient to measure apparent seismic time dip $\left(p_{x}, p_{y}\right)$ components along inline and cross-line directions. For depth-migrated seismic data, such as our Cuu Long survey, we compute $\theta_{x}$ and $\theta_{y}$ and display them either as components or as dip magnitude, $\theta$, and dip azimuth, $\psi$, or alternatively as dimensionless $\left(p_{x}, p_{y}\right)$ measured. The relationship between apparent seismic time/depth dips and apparent angle dips are:

$$
p_{x}=2 * \tan \theta_{x} / v \text { and } p_{y}=2 * \tan \theta_{y} / v,
$$

where $v$ is an average time to depth conversion velocity. We can compute apparent dip at any angle $\psi$ from the north through a simple trigonometric rotation (Marfurt 2006):

$$
p_{\psi}=p_{x} \cos (\psi-\varphi)+p_{y} \sin (\psi-\varphi),
$$

where $\phi$ is the angle of the inline seismic axis from the north.

Amplitude gradient vector attribute that has inline and cross-line components $\left(g_{x}, g_{y}\right)$ is also described. We can therefore compute an amplitude gradient at any angle, $\psi$, from the north:

$$
g_{\psi}=g_{x} \cos (\psi-\varphi)+g_{y} \sin (\psi-\varphi) .
$$

Using these equations, we are able to animate, through a suite of apparent dip, amplitude gradient images at increments of $30^{\circ}$ to see which perspective best illuminates structural features of interest.

\section{RESULTS}

\subsection{Improvement of seismic signal from fractured basement by using filters}

In order to apply seismic filtering and migration methods for improving seismic signal from fractured basement, we create seismic models representing fractured basement in Cuu Long Basin, with the velocity varying vertically and laterally (Fig. 3).

The models show that there are sedimentary boundaries with strong reflection coefficient that could create strong multiples. The multiples from these boundaries can be imbedded into the lower sections, especially the basement section. With the results from the models, we can improve our 


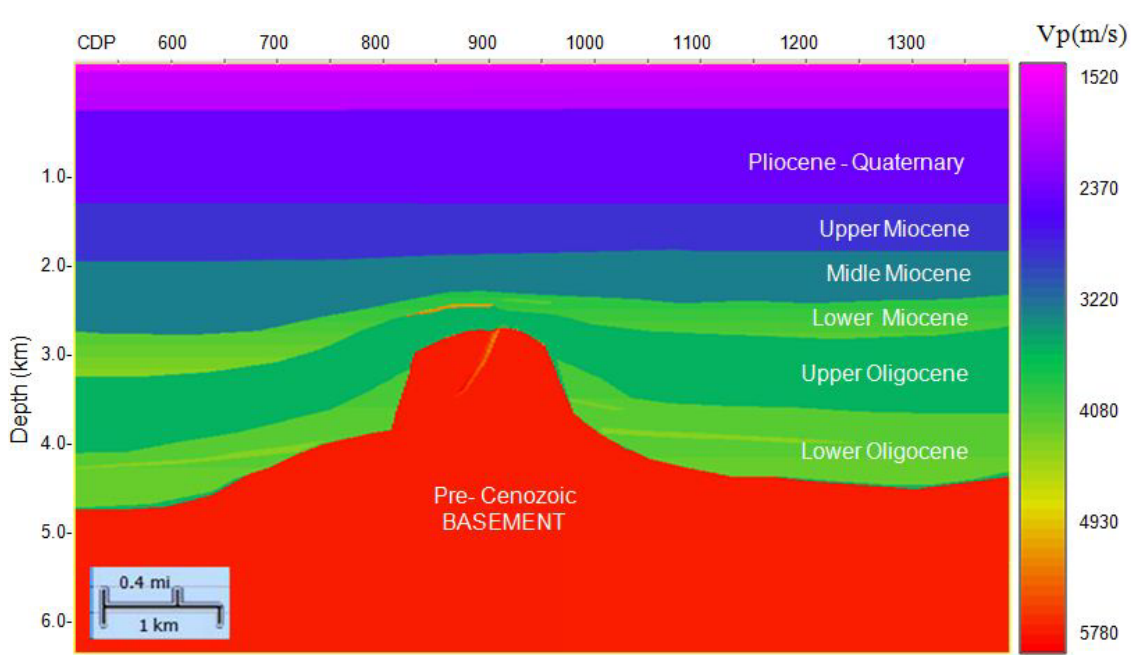

Fig. 3. Seismic velocity model representing fractured basement in Cuu Long Basin.

processing workflow, predict the parameters for the filters for better removing the multiples, and enhance the true signals from the basement. The granite matrix velocity is estimated to be about $5.4-6.0 \mathrm{~km} / \mathrm{s}$; however, some imaging studies show that the velocity for the granite section in the model of about $4.6 \mathrm{~km} / \mathrm{s}$ is more applicable for the migration and stacking response. The velocity contrast between the basement and sedimentary layers varies in different regions. Some parts of the basement covered by lower Oligocene with lower acoustic impedance contrast gives weak seismic response. Characteristics of fractured zone are different from fresh basement; the ratio between $P$ - and $S$-wave velocity in fractured zone increases from 1.7-1.9 to 2.0, and acoustic impedance (AI) decreases by 10\% (Tan 1990).
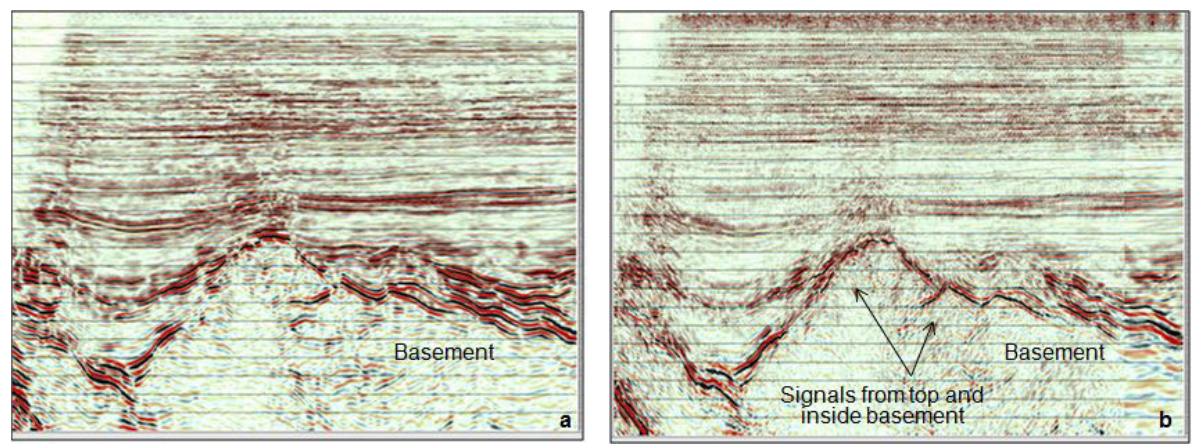

Fig. 4. f-k filtering could improve seismic signal from top and inside the basement: (a) middle and far offset stacked section, (b) middle and far offset stacked section with $\mathrm{f}-\mathrm{k}$ filtering. 
The f-k filtering was applied for full, middle and far offset. Figure 4 shows that by applying f-k filter on middle and far offset, the upper part of basement is significantly improved and the signature of fractured zones within the basement is revealed better.
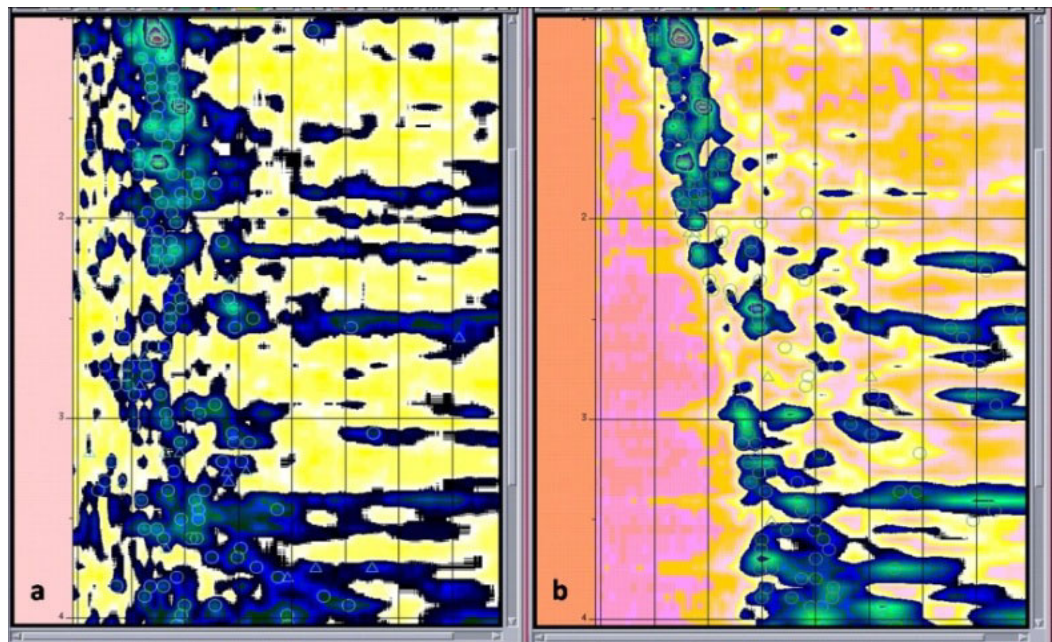

Fig. 5. Enhanced resolution and velocity analysis with Radon transform: (a) velocity spectrum without Radon transform, (b) with Radon transform.

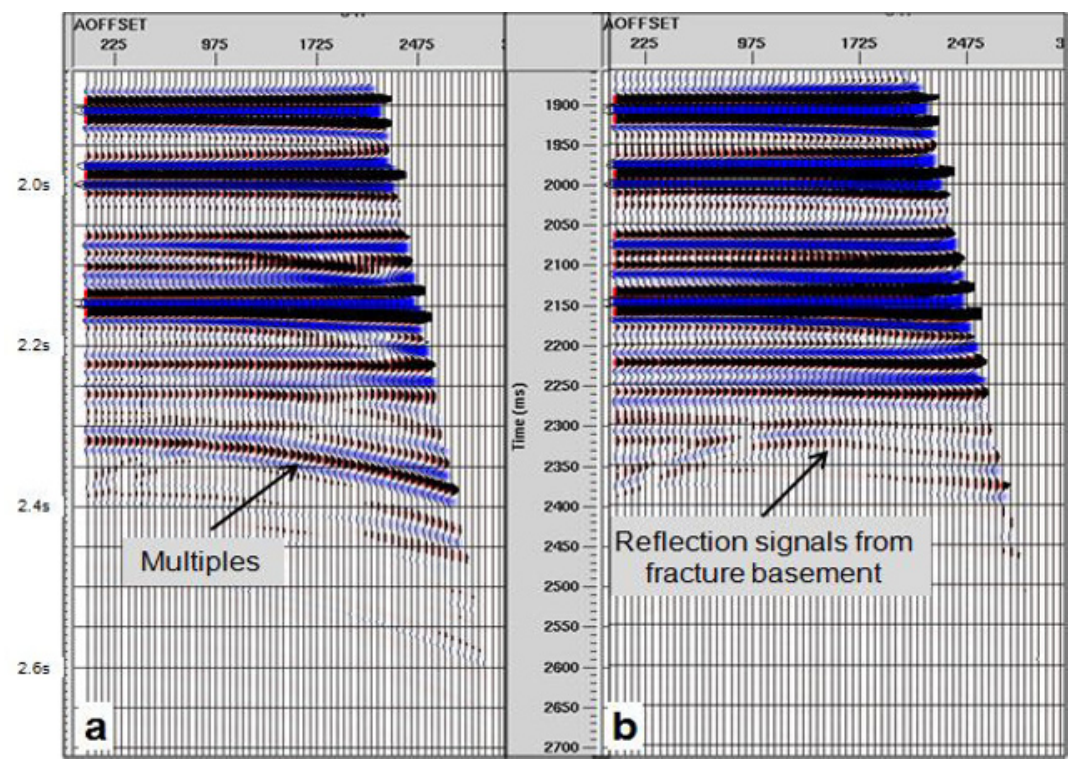

Fig. 6. Enhanced reflection signals from fractured basement with Radon transform: (a) common midpoint gather without Radon transform, (b) with Radon transform. 
When applying Radon transform, the velocity spectrum and resolution is enhanced (Fig. 5), so that the velocity analysis can be done more accurately. With improved velocity analysis using Radon transform, multiples are suppressed, and signals are enhanced. This is especially important for the basement because of its originally weak $\mathrm{S} / \mathrm{N}$ ratio. The signal from fractured system is greatly enhanced, as shown in seismic gather (Fig. 6) and seismic section (Fig. 7).

Figure 8 shows the results of applying combination of Radon transform and Tau-P filters. After effectively eliminating multiples by the Radon transform and Tau-P filtering, reflective signals from the fractured zone within the basement are better visible (Fig. 8b). The faults and fractures can be better interpreted on the filtered data. These results are then verified and conform with sonic, gamma ray characteristics on well data (Fig. 9).
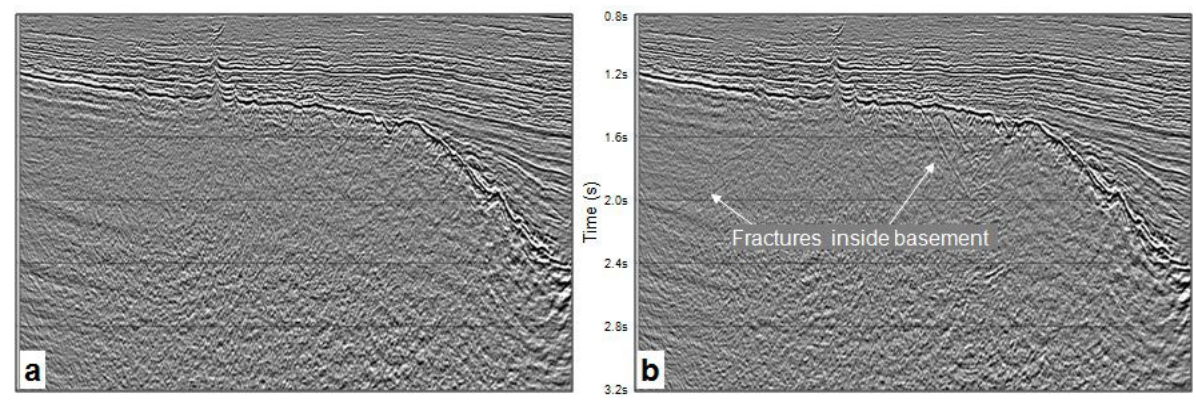

Fig. 7. Compare seismic section before (a) and after velocity accuracy correction (b). In the seismic section (b) the image of fractures on the roof of basement distinguished by the velocity analysis was enhanced.
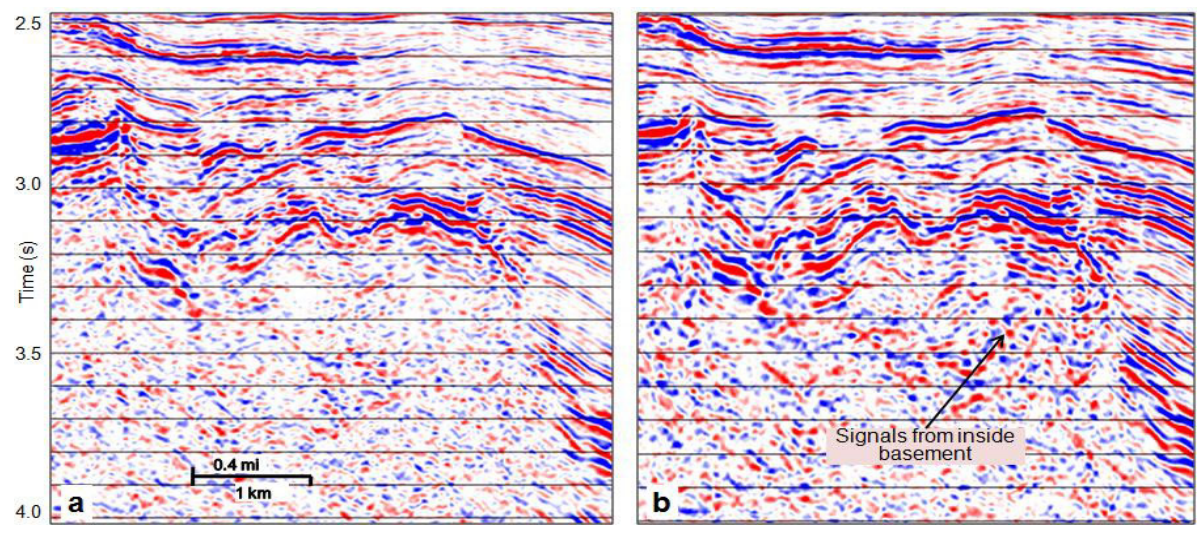

Fig. 8. Seismic section showing the effect of combining Radon transform and Tau-P filter: (a) seismic section, (b) seismic section with Radon transform and Tau-P filter. 


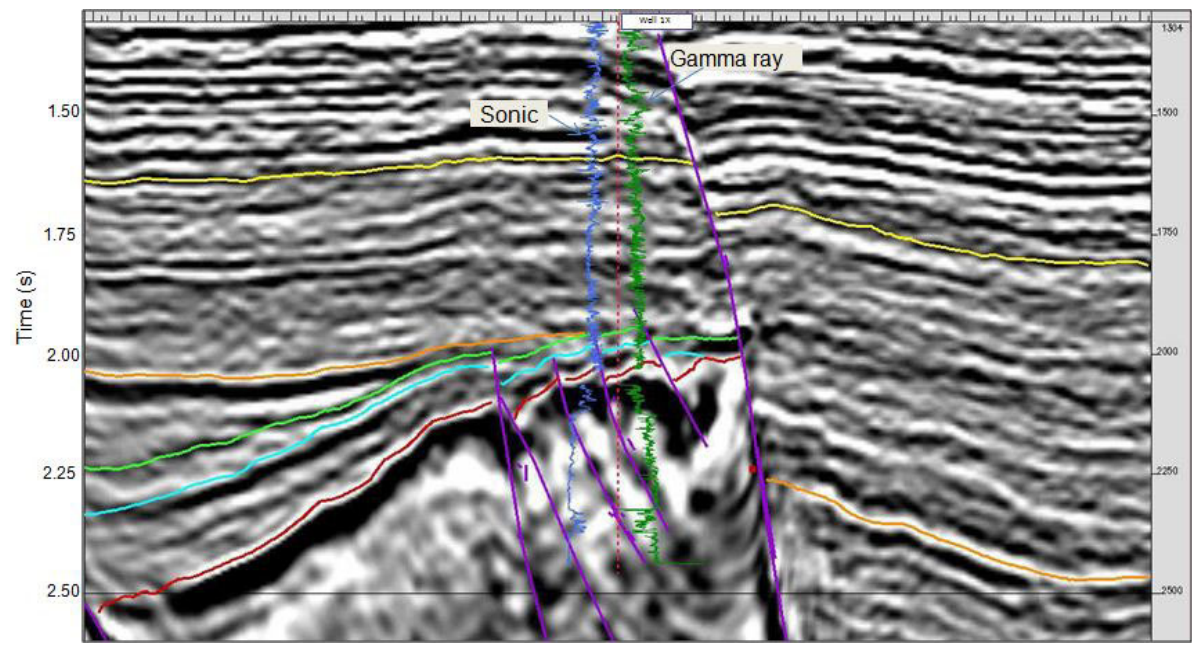

Fig. 9. Reflections from fracture zones have been confirmed by well data.

\subsection{Improving image in fractured basement by Kirchhoff and Control Beam Migration}

In order to qualitatively define the nature of fractures within the basement in Cuu Long Basin, besides using seismic filters, both Kirchhoff Migration and CBM approaches were used for improving image of fractures within the basement. Kirchhoff Migration provides better imaging for both sediments and the top of basement (Fig. 10). Even though the results of Kirchhoff Migration improves the image of fractured basement, it is still necessary to

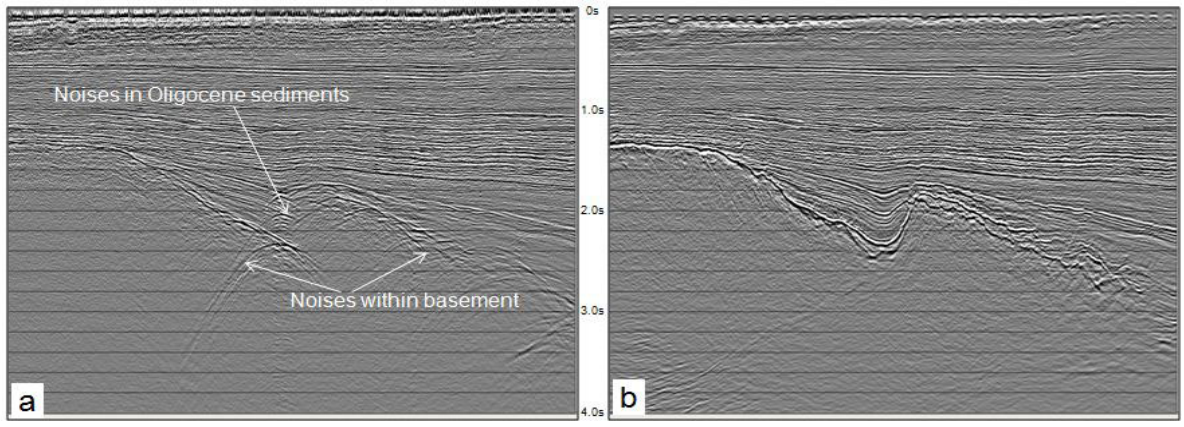

Fig. 10. The quality of seismic section related with top and inside basement is improved by Kirchhoff Migration. (a) Seismic section before using Kirchhoff Migration is of very low quality and contains a lot of noise, (b) Seismic section after using Kirchhoff Migration could provide good imaging for the identification of the cover and within the basement. 

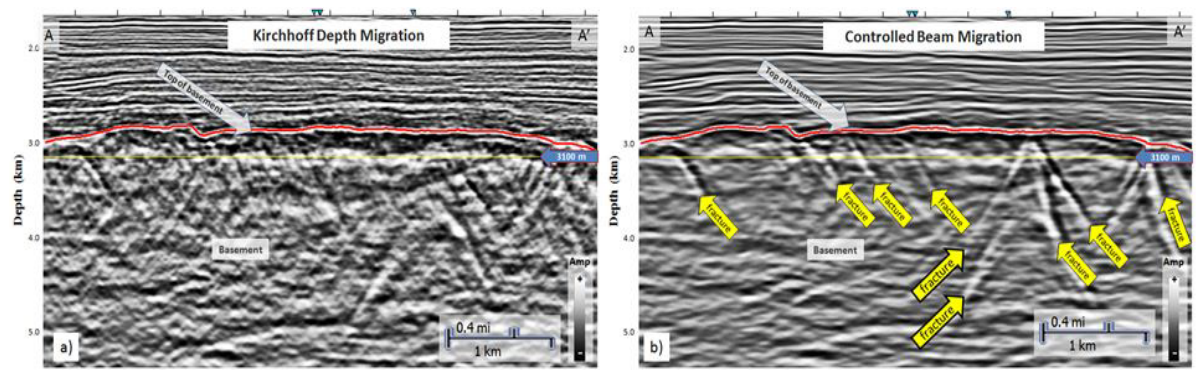

Fig. 11. Comparison of Kirchhoff and Controlled Beam Migration in vertical seismic section (the fault indicates location of depth slice displayed in Fig. 12). (a) Kirchhoff depth migration, (b) Controlled Beam Migration.
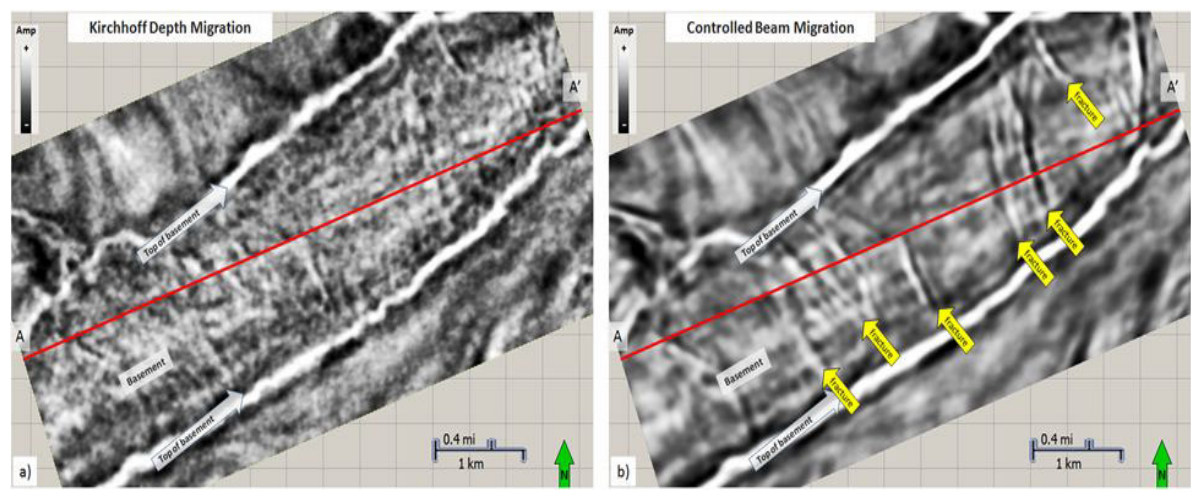

Fig. 12. Comparison of Kirchhoff and Controlled Beam Migration on depth slice at $z=3100 \mathrm{~m}$ (vertical seismic section in line $\mathrm{AA}^{\prime}$ is shown in Fig. 13). (a) Kirchhoff depth migration, (b) Controlled Beam Migration. While the lateral resolution is slightly lower, the Controlled Beam Migration much better indicates the fractures.

apply CBM to solve the imaging problem of the basement, which is naturally complex. Figure 11 shows a comparison of the results applying Kirchhoff Migration and CBM. The faults lineaments are much easier identified in the CBM section, with less noise interfered. A comparison of Kirchhoff Migration and CBM on depth slices $z=3100 \mathrm{~m}$ is shown in Fig. 12. While the lateral resolution is slightly lower, the CBM can indicate fractures much better, which helps improving interpretation.

\subsection{Seismic Attribute illumination of basement faults}

Geometrical Attributes such as structural dip and azimuth and amplitude energy gradients are used to improve locating faults and fractures inside the basement. The results obtained are shown in Figs. 14-17. Figure 14 shows 


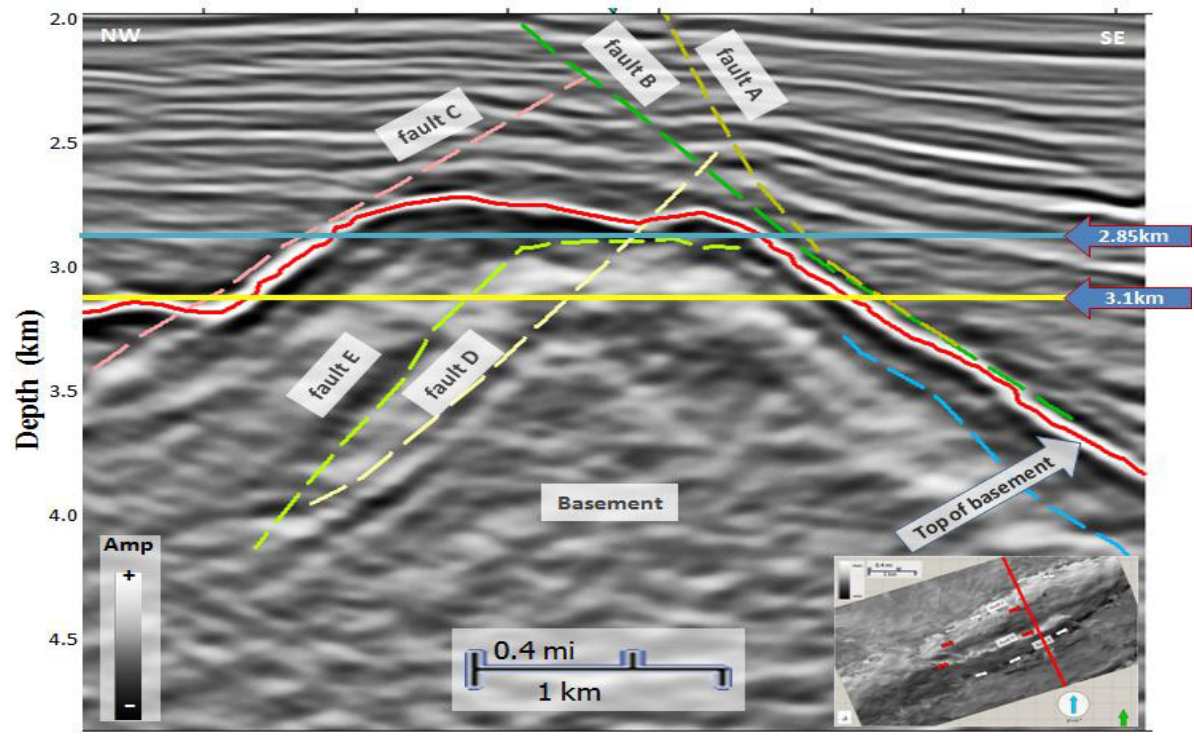

Fig. 13. Vertical seismic section showing top of basement and interpreted faults.

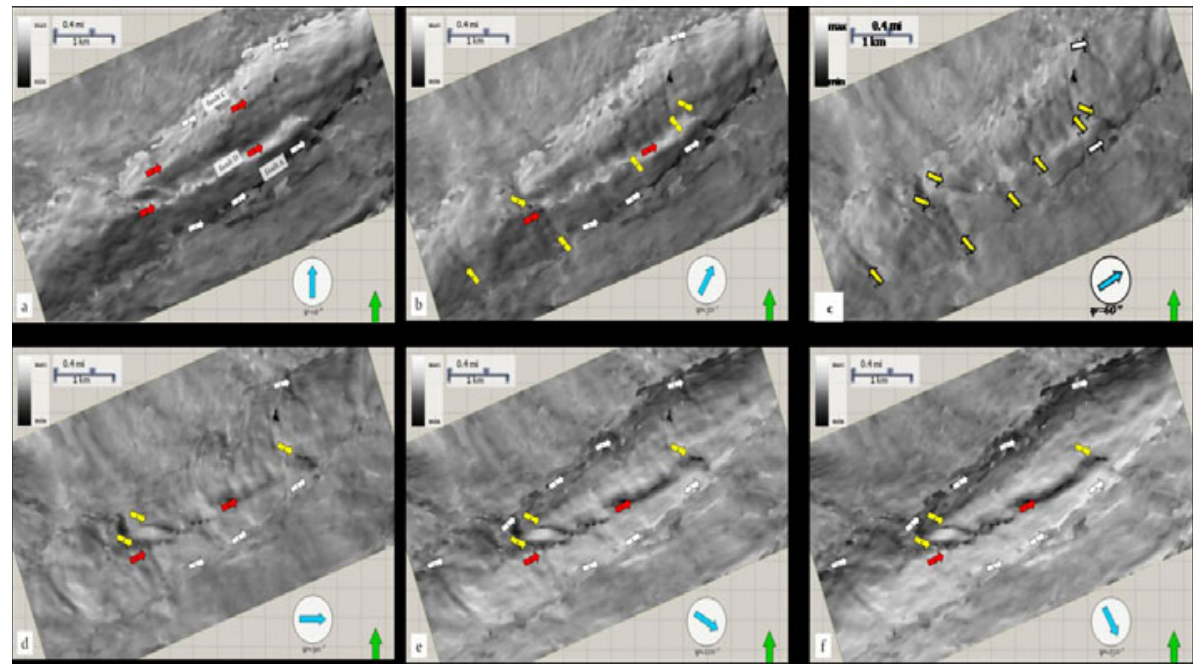

Fig. 14. Depth slices at $z=2850 \mathrm{~m}$ through apparent dip, $p_{y}$, computed at apparent direction $\psi=0^{\circ}(\mathrm{a}), 30^{\circ}(\mathrm{b}), 60^{\circ}(\mathrm{c}), 90^{\circ}(\mathrm{d}), 120^{\circ}(\mathrm{e})$, and $150^{\circ}$ (f) from the north. Arrows (1) indicate lineaments which were interpreted as main NE-SW faults running along basement top. Arrows (2) indicate the faults that cut across the basement, in N-S and NW-SE direction, and Arrows (3) indicate subtle faults running NE-SW and cutting into the basement. 

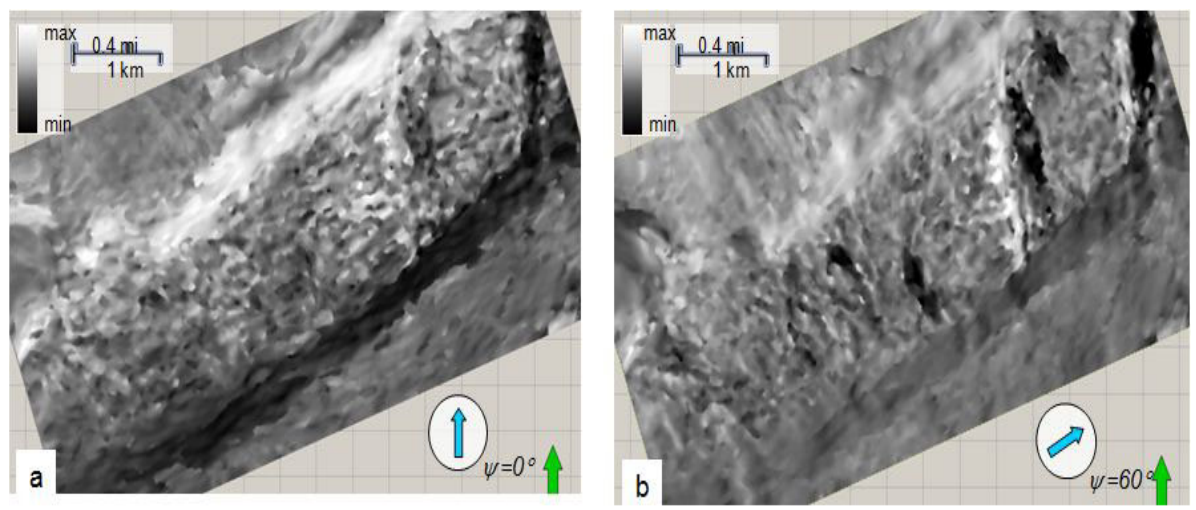

Fig. 15. Depth slices at $z=3100 \mathrm{~m}$ through apparent dip, $p_{\psi}$, computed at apparent direction $\psi=0^{\circ}$ and $60^{\circ}$ from the north.

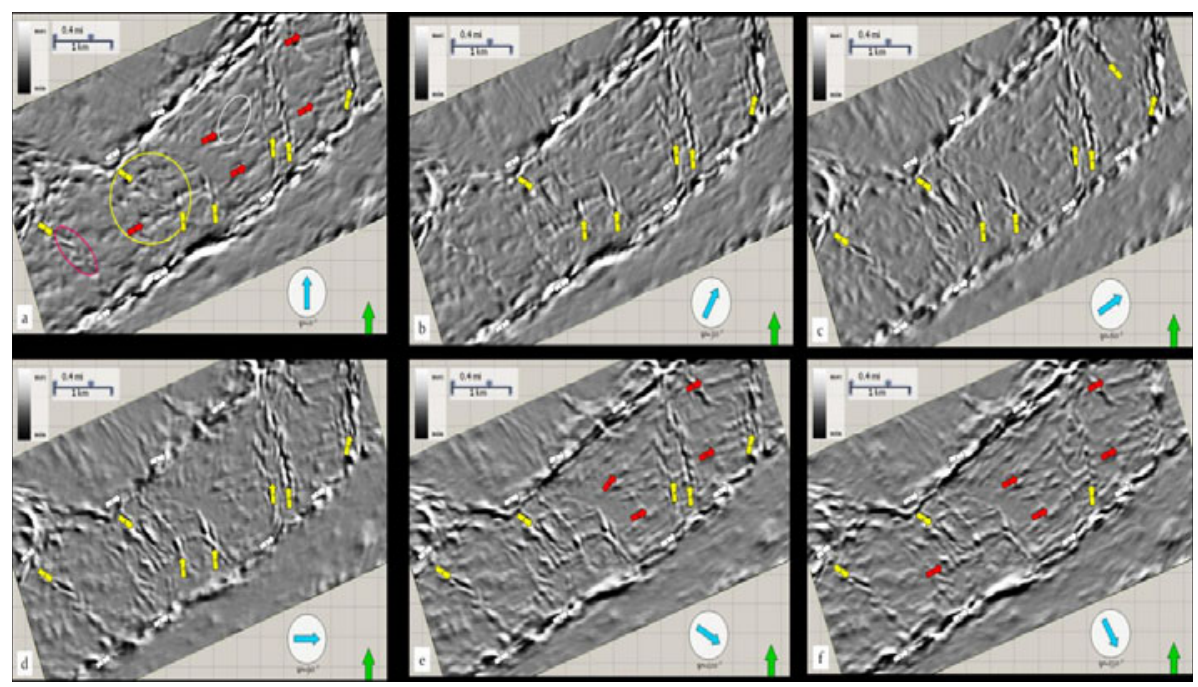

Fig. 16. Depth slices at $z=3100 \mathrm{~m}$ through apparent amplitude gradients, $g_{\psi}$, computed at apparent direction $\psi=0^{\circ}$ (a), 30 ${ }^{\circ}$ (b), 60 $(\mathrm{c}), 90^{\circ}$ (d), $120^{\circ}$ (e), and $150^{\circ}$ (f) from the north. White arrows (1) indicate lineaments which were interpret as main NE-SW faults running along basement top. Yellow arrows (2) indicate the faults that cut across the basement, in N-S and NW-SE direction. Red Arrows (3) indicate subtle faults running NE-SW and cutting into the basement.

depth slices at the top of basement level $(2850 \mathrm{~m})$ through the apparent dip volume, $p_{\psi}$, as a function of azimuth, using the equation in Subsection 3.3 for $\psi=0^{\circ}, 30^{\circ}, 60^{\circ}, 90^{\circ}, 120^{\circ}$, and $150^{\circ}$. In these depth slices through the 


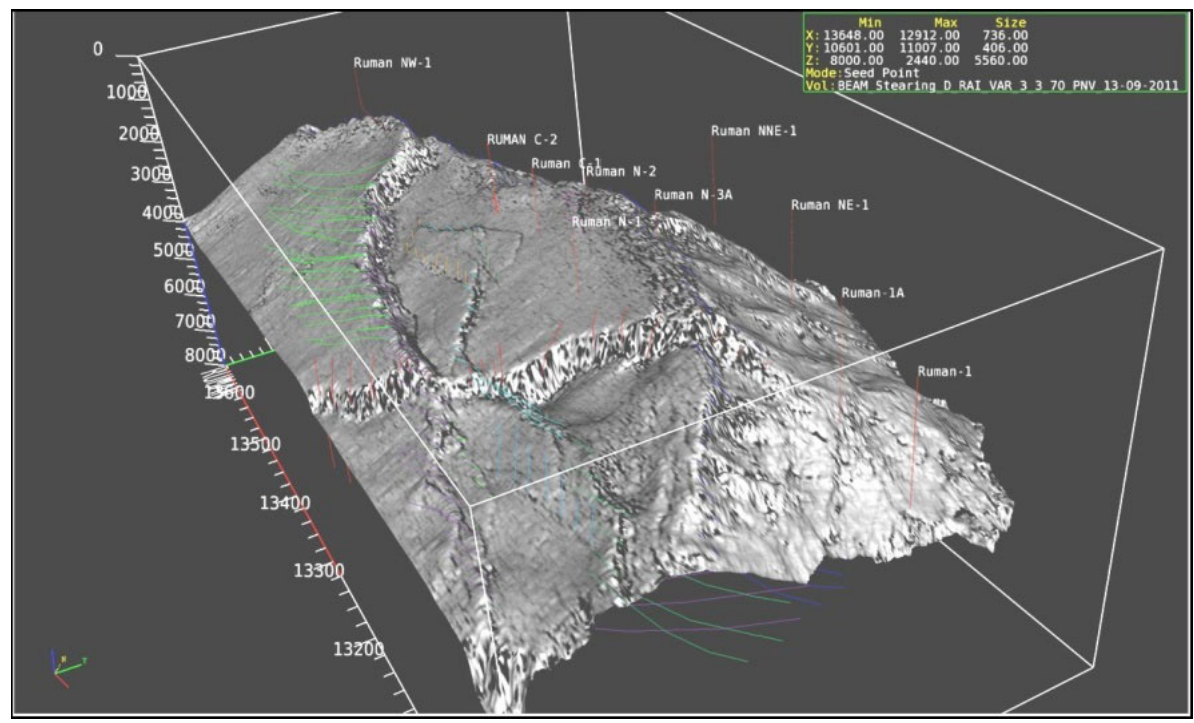

Fig. 17. Curvature, dip and azimuth attributes of top basement in 3D cube.

apparent dip, the NE-SW major faults running along the basement top, the $\mathrm{N}-\mathrm{S}$ and NW-SE faults cutting across the basement, and the NE-SW subtle faults cutting into the basement have appeared clearer. The reflector dip enhances different lineament features as the direction of illumination is rotated, as we can see by comparing Figs. 15a and 15b. Since the dip attribute measures the dip of a reflector surface, the dip attribute computed on or near the top of basement reveals lineaments well. However, if we look deeper inside the basement, the dip estimates become noisier, making it harder to interpret the results.

In contrast, amplitude gradients are computed along local dip and better delineate high energy cross-cutting fractures. Apparent amplitude energy gradient results were generated at the illumination direction $\psi=0^{\circ}, 30^{\circ}$, $60^{\circ}, 90^{\circ}, 120^{\circ}$, and $150^{\circ}$ from the north. Figure 16 shows depth slice at $3100 \mathrm{~m}$ cutting through the top of the granite basement. In this depth slices through apparent amplitude gradients, the faults like the ones shown in Fig. 14 are distinguished. From the results of study of structural dip and azimuth and amplitude energy gradients, the imaging of faults and fractured on the top basement expressed in 3D cube (Fig. 17).

\section{CONCLUSIONS}

Highly fractured zones in pre-Cenozoic, structurally complex granitic basement highs in the Cuu Long Basin form potential petroleum reservoirs. The 
seismic data quality of these sections is poor with the interference of strong noise and multiple reflections.

The application of combining filtering techniques, including $\mathrm{f}-\mathrm{k}$, Tau-P, and Radon transform, enhances signal-to-noise ratio significantly and allows to image the fractured basement signal better.

Kirchhoff Migration and Controlled Beam Migration, on the other hand, effectively image the top basement and intra-basement events in which the image quality of CBM is clearly superior to that of Kirchhoff Migration. Geometric attributes such as dip and amplitude energy gradients, are multicomponent in nature and are thus amenable to visualization from different user-controlled perspectives.

Thus, the application of a suite of filters, migrations, and attribute analysis enhances the clarity of internal structures within the basement complexes within the Cuu Long Basin such as faults and fractures that might otherwise be miss-interpreted.

Acknowledgements. This work is funded by the Vietnam's National Foundation for Science and Technology Development (NAFOSTED), Project No. 105.04.27.09. The support by PetroVietnam and OU AttributeAssisted Seismic Processing and Interpretation (AASPI) consortium is acknowledged.

\section{References}

Areshev, E.G., T.L. Dong, N.T. San, and O.A. Shnip (1992), Reservoirs in fractured basement on the continental shelf of Southern Vietnam, J. Petrol. Geol. 15, 4, 451-464, DOI: 10.1111/j.1747-5457.1992.tb01045.x.

Barnes, A.E. (2003), Shaded relief seismic attribute, Geophysics 68, 4, 1281-1285, DOI: $10.1190 / 1.1598120$.

Benoliel, S.D., W.A. Schneider, and R.N. Shurtleff (1987), Frequency wavenumber approach of the Tau-P transform: Some applications in seismic data processing, Geophys. Prospect. 35, 5, 517-538, DOI: 10.1111/j.1365-2478. 1987.tb00833.x.

Bone, G., N.T. Giang, D.N. Quy, V.N. An, D. Pham, J. Sun, and Q. Tang (2008), Improvements in seismic imaging in fractured basement, Block 15-1, Offshore Vietnam: Fractured basement reservoir, Petrovietnam Rev. 4, 63-69.

Chapman, C.H. (1981), Generalized Radon transforms and slant stacks, Geophys. J. Roy. Astr. Soc. 66, 2, 445-453, DOI: 10.1111/j.1365-246X.1981.tb05966.x.

Chopra, S., and K.J. Marfurt (2007), Seismic Attributes for Prospect Identification and Reservoir Characterization, SEG Geophysical Developments Series, No. 11, Society of Exploration Geophysicists, Tulsa, USA, 456 pp. 
Cuong, T.X., and J.K. Warren (2009), Bach Ho field, a fractured granitic basement reservoir, Cuu Long basin, offshore SE Vietnam: a "Buried-Hill" play, J. Petrol Geol. 32, 2, 129-156, DOI: 10.1111/j.1747-5457.2009.00440.x.

Dong, H.N. (2012), Geological and tectonic characterization in the Northern part of Cuu Long Basin during Eocene-Oligocene, Ph.D. Thesis, Hanoi University of Mining and Geology, Hanoi, Vietnam.

Dong, T.L., P.H. Long, H.V. Quy, P.D. Hai, and T.S. Hau (1999) Distribution of fractures, faults and their formation in the basement of South Vietnam continental shelf and adjacent areas, Petrovietnam Rev. 3, 4-13.

Duc, N.A. (2014), Characteristics of Pre-Tertiary fractured granitoid basement in Hai Su Den field, Cuu Long basin, Petrovietnam J. 5, 15-22.

Duncan, G., and G. Beresford (1994), Slowness adaptive f-k filtering of prestack seismic data, Geophysics 59, 1, 140-147, DOI: 10.1190/1.1443525.

Elkady, N., Y.C. Tan, R. Baker, Z.J. Zhou, and A. Tan (2008), Imaging improvement of fractured and faulted basement through Controlled Beam Migration. Examples from Diamond field in Vietnam. In: International Petroleum Technology Conference, Kuala Lumpur, Malaysia.

Foster, D.J., and C.C. Mosher (1992), Suppression of multiple reflections using the Radon Transform, Geophysics 57, 3, 386-395, DOI: 10.1190/1.1443253.

Gardner, G.H.F. (1985), Migration of Seismic Data, SEG Monograph Series, $462 \mathrm{pp}$.

Gray, S.H., Y. Xie, C. Notfors, T. Zhu, D. Wang, and C. Ting (2009), Taking apart Beam Migration, The Leading Edge 28, 9, 1098-1108, DOI: 10.1190/ 1.3236380 .

Gwang, H.L., L. Keumsuk, and J.S. Watkins (2001), Geologic evolution of the Cuu Long and Nam Con Son basins, offshore Southern Vietnam, South China Sea, AAPG Bull. 85, 6, 1055-1082.

Ha, M.T., O. Elebiju, and K.J. Marfurt (2014), Attribute illumination of basement faults, examples from Cuu Long Basin basement, Vietnam and the Midcontinent, USA, Interpretation 2, 1, SA119-SA126, DOI: 10.1190/INT-20130091.1.

Hill, N.R. (2001), Prestack Gaussian-Beam depth migration, Geophysics 66, 4, 1240-1250, DOI: 10.1190/1.1487071.

Le Pichon, X., M. Fournier, and L. Jolivet (1992), Kinematic, topography, shortening, and extrusion in the India-Eurasia collision, Tectonics 11, 6, 1085 1089, DOI: $10.1029 / 92$ TC01566.

Marfurt, K.J. (2006), Robust estimates of 3D reflector dip and azimuth, Geophysics 71, 4, 29-40, DOI: 10.1190/1.2213049.

Raz, S. (1987), Beam stacking: a generalized preprocessing technique, Geophysics 52, 9, 1194-1210, DOI: 10.1190/1.1442383.

San, N.T., N. Giao, and T.L. Dong (1997), Pre-Tertiary basement - The new objective for oil and gas exploration and production in the Continental Shelf of 
South Vietnam. In: Proc. Int. Conf. on Petroleum Systems of SE Asia and Australia, 461-465.

Sheriff, R.E. (1999), Encyclopedic Dictionary of Exploration Geophysics, SEG.

Sun, J., P. Don, J. Sun, Q. Tang, G. Bone, and N.T. Giang (2007), Imaging of fractures and faults inside granite basement using controlled beam migration. In: ASEG 19th International Geophysical Conference \& Exhibition.

Sun, Y., F. Qin, S. Checkles, and J.P. Leveille (2000), 3D Prestack Kirchhoff Beam Migration for depth imaging, Geophysics 65, 5, 1592-1603, DOI: 10.1190/ 1.1444847 .

Tan, M.T. (1990), The enhancement of seismic prospecting effectiveness for oil and gas under the conditions of the sedimentary basins in the continental shelf of Vietnam, Zesz. Nauk AGH Geofiz. Stos. Bull. 6, 1323, 142.

Tan, M.T. (1995), Seismic stratigraphic studies of the continental shelf of Southern Vietnam, J. Petrol. Geol. 18, 3, 345-354, DOI: 10.1111/j.1747-5457.1995. tb00910.x.

Tan, M.T., and M.T. Ha (2013), Enhancement of the seismic technology to improve imaging quality of fractured reservoir inside granite basement. In: Proc. 11th SEGJ Int. Symp., Yokohama, Japan, 160-163.

Tan, M.T., and N.Q. Thap (2001), The possibility of applying geophysical methods to study fractured basement reservoir in the continental shelf of Vietnam. In: Proc. Offshore Technology Conf., 451-456.

Tan, T.K., and N.Q. Bo (1997), Geological modeling and reservoir properties of basement rocks of the South Vietnam continental shelf. In: Proc. Int. Conf. on Petroleum Systems of SE Asia and Australia, 539-544.

Tapponier, P., M. Peltzer, and R. Armijor (1986), On the mechanisms of the collision between India and Asia, Geol. Soc. London Spec. Publ. 19, 115-157.

van der Baan, M., and J.M. Kendall (2002), Estimating anisotropy parameters and traveltimes in the $\tau$-p domain, Geophysics 67, 4, 1076-1086, DOI: 10.1190/ 1.1500368 .

Wang, B., and K. Pann (1996), Kirchhoff migration of seismic data compressed by matching pursuit decomposition. In: SEG Technical Program Expanded Abstracts, 1642-1645.

Yilmaz ,O. (2001), Seismic Data Analysis. Processing, Inversion, and Interpretation of Seismic Data, Series: Investigations in Geophysics, Vol. 1, Society of Exploration Geophysicists, Tulsa, USA.

Received 7 October 2015

Received in revised form 17 December 2015

Accepted 8 February 2016 